\title{
Erratum to: Impaired diffusing capacity for carbon monoxide in children with type 1 diabetes: is this the first sign of long-term complications?
}

\author{
Andrea E. Scaramuzza - Marco Morelli - Maurizio Rizzi • \\ Simona Borgonovo - Alessandra De Palma - Chiara Mameli • \\ Elisa Giani · Silvia Beretta • Gian Vincenzo Zuccotti
}

Published online: 17 January 2012

(C) Springer-Verlag 2012

Erratum to: Acta Diabetol

DOI 10.1007/s00592-011-0353-2

In the reference no. 18 , the name of the first author was incorrectly rendered as B van den Boost. The correct name is B van den Borst.

The online version of the original article can be found under doi:10.1007/s00592-011-0353-2.

A. E. Scaramuzza - M. Morelli $\cdot$ S. Borgonovo - A. De Palma C. Mameli · E. Giani · S. Beretta - G. V. Zuccotti Department of Paediatrics, "Luigi Sacco Hospital", University of Milano, Via G.B. Grassi 74, 20157 Milan, Italy

A. E. Scaramuzza $(\bowtie)$

Department of Pediatrics, "Ospedale Luigi Sacco",

University of Milano, Via G.B. Grassi 64, 20154 Milan, Italy

e-mail: scaramuzza.andrea@hsacco.it

M. Rizzi

Respiratory Medicine, Luigi Sacco Hospital,

University of Milano, Via G.B. Grassi 74, 20157 Milan, Italy 